\title{
Ag-Cu Bimetallic Nanoparticles Prepared by Microemulsion Method as Catalyst for Epoxidation of Styrene
}

\author{
Hong-Kui Wang, ${ }^{1}$ Chao-Yong Yi, ${ }^{1}$ Li Tian, ${ }^{2}$ Wen-Juan Wang, ${ }^{1}$ Jian Fang, ${ }^{1}$ \\ Ji-Hua Zhao, ${ }^{1}$ and Wei-Guo Shen ${ }^{3}$ \\ ${ }^{1}$ School of Chemistry and Chemical Engineering, Lanzhou University, Lanzhou 730000, China \\ ${ }^{2}$ The Chemistry Department, Fudan University, Shanghai 200433, China \\ ${ }^{3}$ School of Chemistry and Chemical Engineering, East China University of Science and Technology, Shanghai 200237, China
}

Correspondence should be addressed to Ji-Hua Zhao, zhaojihua@lzu.edu.cn

Received 8 April 2011; Revised 17 June 2011; Accepted 10 July 2011

Academic Editor: Mohammad Reza Bayati

Copyright (C) 2012 Hong-Kui Wang et al. This is an open access article distributed under the Creative Commons Attribution License, which permits unrestricted use, distribution, and reproduction in any medium, provided the original work is properly cited.

$\mathrm{Ag} / \mathrm{Cu}$ bimetallic nanocatalysts supported on reticulate-like $\gamma$-alumina were prepared by a microemulsion method using $\mathrm{N}_{2} \mathrm{H}_{4} \cdot \mathrm{H}_{2} \mathrm{O}$ as the reducing agent. The catalysts were activated by calcination followed with hydrogen reduction at $873 \mathrm{~K}$, and the properties were confirmed using various characterization techniques. Compared with metal oxides particles, Ag-Cu particles exhibited smaller sizes $(<5 \mathrm{~nm})$ after calcination in $\mathrm{H}_{2}$ at $873 \mathrm{~K}$. XPS results indicated that the binding energies changed with the $\mathrm{Ag} / \mathrm{Cu}$ ratios, suggesting that increasing the copper content gave both metals a greater tendency to lose electrons. Furthermore, $\mathrm{Ag}$-Cu bimetallic nanoparticles supported on $\gamma$-alumina showed better catalytic activity on the epoxidation of styrene as compared with the corresponding monometallic silver or copper. The styrene oxide selectivity could reach $76.6 \%$ at $\mathrm{Ag} / \mathrm{Cu}$ molar ratio of $3 / 1$, while the maximum conversion (up to $94.6 \%$ ) appeared at $\mathrm{Ag} / \mathrm{Cu}$ molar ratio of $1 / 1$ because of the maximum interaction between silver and copper.

\section{Introduction}

In recent years, research on silver, copper and gold nanoparticles used as catalysts in CO redox reactions [1-3], NOx reduction $[4,5]$ and epoxidation of alkenes [6-9] has made great progress. Because of an altered electronic or surface structure of the metal particles, metal nanoparticle catalysts composed of two (or more) different metal elements may result in improved catalyst quality or properties and hence are of great interest from both technological and scientific views [10]. There have been several reports on the synthesis and assembly of bimetal materials such as Pd-Pt [11], AuAg [3], Pt-Co [12], and Ni-Mo [13]. Especially, Agrawal et al. [14] made a series of studies on bimetallic or multimetallic nanoparticle catalysts, for example, $\mathrm{Au}-\mathrm{Ag}, \mathrm{Au}-\mathrm{Cu}$, and $\mathrm{Au}-\mathrm{Ag}-\mathrm{Cu}$. Alumina-based supports are often used in these catalysts because of their mechanical and chemical resistance under reaction conditions. For instance, an alumina supported silver/copper catalyst has a higher ammonia oxidation activity than catalysts with pure silver or copper particles [15].

Although the $\mathrm{Ag}-\mathrm{Cu}$ catalyst system has shown excellent catalytic activity in many oxidation reactions, an attempt about using $\mathrm{Ag}-\mathrm{Cu}$ as catalyst for oxidation of styrene is rarely reported. Oxidation of styrene may be regarded as a very strategic reaction in industrial applications, because styrene oxide (a main product of oxidation of styrene) is one of the most important fine chemical intermediates for producing perfume, drugs, sweeteners, epoxy resins, and so forth [16]. However, it is difficult to find a catalyst that accelerates both conversion and selectivity for this reaction. To solve this problem, $\mathrm{Ag}-\mathrm{Cu}$ systems are tested herein to see whether this catalyst could meet the requirements.

In order to better understand the working mechanism of such catalysts, it is essential to prepare model systems with a high degree of control over the particle size of the active material. In the past decade, several methods have been used to produce supported catalysts, but it is difficult 
to immobilize the nanoparticles on catalyst supports without large aggregates. Water-in-oil microemulsions are transparent, isotropic, and thermodynamically stable nanosized water droplets that are dispersed in a continuous oil phase and stabilized by surfactant molecules at the water/oil interface [17]. This technique has been used for synthesizing various of nanosized particles, such as $\mathrm{Cu}$ [18], Au-Ag [17], $\mathrm{KCoFePBA}$ [19], and $\gamma-\mathrm{Al}_{2} \mathrm{O}_{3}$ nanoparticles [20]. It is suitable for the preparation of particles, because not only the size but also the shape of the particles can be controlled by altering the water-to-surfactant molar ratio $(\omega)$ appropriately. The unique advantages of this method, compared to other techniques for controlled nanoparticle preparation, are that the particles can be formed at atmospheric pressure and at room temperature and that large sample volumes can be obtained relatively easily [21].

In this study, we have investigated the deposition of Ag$\mathrm{Cu}$ bimetallic nanoparticles by the coreduction of $\mathrm{Ag}^{+}$and $\mathrm{Cu}^{2+}$ with $\mathrm{N}_{2} \mathrm{H}_{4} \cdot \mathrm{H}_{2} \mathrm{O}$ as reductant, prepared in w/o microemulsions, on reticulate-like $\gamma$-alumina particles which are obtained through the microemulsion technique by our group [22]. After calcination and reduction at $873 \mathrm{~K}$ for one hour by $\mathrm{H}_{2}$, these materials were characterized by several techniques in order to determine their physicochemical compositions. Finally, the performances of catalysts with different molar ratios of $\mathrm{Ag} / \mathrm{Cu}$ supported on $\gamma$-alumina were tested by epoxidation of styrene under mild conditions.

\section{Experimental Section}

2.1. Chemicals. The nonionic surfactant Triton $\mathrm{X}-100[p-$ tert- $\left.\mathrm{C}_{8} \mathrm{H}_{17} \mathrm{C}_{6} \mathrm{H}_{4}\left(\mathrm{OC}_{2} \mathrm{H}_{4}\right)_{9.5} \mathrm{OH}\right]$ was obtained from SigmaAldrich. Cyclohexane $\left(\mathrm{C}_{6} \mathrm{H}_{12}\right.$, A.R.) used as oil phase and $n$ butanol $\left[\mathrm{CH}_{3}\left(\mathrm{CH}_{2}\right)_{2} \mathrm{CH}_{2} \mathrm{OH}, \mathrm{A}\right.$.R.] used as the cosurfactant were both purchased from Tianjin Chemical Reagent Limited Company. Silver nitrate $\left(\mathrm{AgNO}_{3}\right.$, A.R.) was product from Beijing Beihua Fine Chemical Reagent Co., Ltd., Cupric nitrate $\left[\mathrm{Cu}\left(\mathrm{NO}_{3}\right)_{2} \cdot 3 \mathrm{H}_{2} \mathrm{O}, 99.5 \%\right.$, A.R.] was received from the Third Branch of Tianjin Chemical Reagent Liu Chang. Aluminum nitrate nonahydrate $\left(\mathrm{Al}\left(\mathrm{NO}_{3}\right)_{3} \cdot 9 \mathrm{H}_{2} \mathrm{O}\right.$, A.R.) was purchased from $\mathrm{Xi}^{\prime}$ an Chemical Reagent Factory. Ammonia $\left(\mathrm{NH}_{3} \cdot \mathrm{H}_{2} \mathrm{O}, 30 \%\right.$, A.R.) was Baiyin LiangYou Chemical Reagent Limited Company products. Styrene $\left(\mathrm{C}_{8} \mathrm{H}_{8}\right.$, C.P. $)$ and bromobenzene $\left(\mathrm{C}_{6} \mathrm{H}_{5} \mathrm{Br}\right.$, A.R.) were bought from Sinopharm Chemical Reagent Limited Company. Hydrazine hydrate $\left(\mathrm{H}_{2} \mathrm{~N} \cdot \mathrm{NH}_{2} \cdot \mathrm{H}_{2} \mathrm{O}, 80.0 \%\right.$, A.R.) was reductant from Tianjin Institute of Fine Chemicals Retrocession. Acetonitrile $\left(\mathrm{CH}_{3} \mathrm{CN}\right.$, A.R.) used as solvents was received from Tianjin Chemical Reagent Limited Company and tert-butyl hydroperoxide (TBHP) $\left[\mathrm{C}_{4} \mathrm{H}_{10} \mathrm{O}_{2}, 70 \%\right.$, C.P.] used as oxidant was bought from Shanghai Sanpu chemical Co., Ltd., Double distilled water was used throughout the experiments.

2.2. Instrumentation. The actual total metal loadings and the $\mathrm{Ag} / \mathrm{Cu}$ molar ratios of various $\mathrm{Ag}-\mathrm{Cu} / \mathrm{Al}_{2} \mathrm{O}_{3}$ samples were determined by the inductively coupled plasma spectrometer on an IRIS ER/S PHEMO instrument. Energy-dispersive Xray spectroscopy (EDS) (JSM-5600LV, KEVEX) and inductively coupled plasma (ICP) (IRIS ER/S, U.S. PHEMO company) confirmed the molar ratios of $\mathrm{Ag} / \mathrm{Cu}$. Chemical composition information about the samples was obtained by $\mathrm{X}$-ray photoelectron spectroscopy (XPS). The measurement was carried out on a PHI-5702 multifunctional spectrometer using $\mathrm{Al} \mathrm{K} \alpha$ radiation, and the binding energies were referenced to the $\mathrm{C} 1 \mathrm{~s}$ line at $284.8 \mathrm{eV}$ from adventitious carbon. All the peaks were fitted using the XPSPEAK version 4.0 peak-fitting program. The specific surface areas of the catalysts and the $\gamma-\mathrm{Al}_{2} \mathrm{O}_{3}$ support were calculated by applying the BET method to the $\mathrm{N}_{2}$ adsorption isotherms, measured at liquid nitrogen temperature on a micromeritics ASAP 2010 apparatus. Rigaku D/MAX-2400 XRD with graphite monochromatized $\mathrm{Cu} \mathrm{K} \alpha$ radiation $(\lambda=0.15406 \mathrm{~nm})$ was used for recording X-ray diffraction (XRD) pattern operating at $40 \mathrm{kV}$ and $40 \mathrm{~mA}$ in the $2 \theta$ range of $10^{\circ}-90^{\circ}$. Transmission electron microscopy (TEM) was performed by using a Hitachi $\mathrm{H}-600$ at an accelerating voltage of $100 \mathrm{kV}$ to examine the morphology and dimension of the $\mathrm{Ag}-\mathrm{Cu}$ nanoparticles as well as nanoalumina. Whether the Ag-Cu nanoparticles supported on the alumina or not was shown clearly via this testing technique. The infrared spectroscopy (IR) spectra were recorded on a NEXUS670 FT-IR spectrometer with samples prepared as $\mathrm{KBr}$ pellets. The products of reaction were detected by Gas Chromatography (GC) on a CP3380 instrument.

2.3. Synthesis. Catalysts of Ag-Cu nanoparticles supported on $\gamma$-alumina were synthesized by microemulsion technology (Triton X-100/n-butanol/cyclohexane/water system) [22]. Briefly, $\mathrm{AgNO}_{3}$ and $\mathrm{Cu}\left(\mathrm{NO}_{3}\right)_{2}$ microemulsion with different $\mathrm{Ag} / \mathrm{Cu}$ atomic ratios as well as the hydrazine hydrate microemulsion were obtained with the same component ratio as the $\mathrm{Al}\left(\mathrm{NO}_{3}\right)_{3}$ microemulsion. Ammonia microemulsion was added dropwise into $\mathrm{Al}\left(\mathrm{NO}_{3}\right)_{3}$ microemulsion with a speed at $4-5 \mathrm{~s} / \mathrm{d}$ accompanied by stirring. After ammonia microemulsion was dropwised up, 40-minute more reaction time was needed. At the fixed temperature of $293 \mathrm{~K}$, various atomic ratios $\mathrm{AgNO}_{3}$ and $\mathrm{Cu}\left(\mathrm{NO}_{3}\right)_{2}$ microemulsion were added directly, meanwhile, vigorously stirred for one hour. Thereafter, hydrazine hydrate microemulsion was thrown into the mixture at the same speed $4-5 \mathrm{~s} / \mathrm{d}$ in order to obtain Ag-Cu bimetallic nanoparticles supported on Aluminum hydroxide. After the total mixture was continuously stirred for 2.5 hours at $293 \mathrm{~K}$, the precipitates were centrifuged one time at $12000 \mathrm{rpm}$ for $40 \mathrm{~s}$ and then calcined in air at $893 \mathrm{~K}$ for 4 hours. Finally, the solids were reduced at $873 \mathrm{~K}$ in $\mathrm{H}_{2}$ $(0.15 \mathrm{~mL} / \mathrm{min})$ for one hour, subsequently cooled to room temperature under $\mathrm{N}_{2}$ flow $(0.15 \mathrm{~mL} / \mathrm{min})$ to obtain the Ag$\mathrm{Cu} / \mathrm{Al}_{2} \mathrm{O}_{3}$ catalyst. In all cases, the nominal total metal loading was $2 \mathrm{wt} \%$.

2.4. Catalytic Reaction Tests. The activity of the supported $\mathrm{Ag}-\mathrm{Cu}$ materials was investigated in the epoxidation of styrene. Before the measurement, the catalyst was prereduced in situ in $99 \% \mathrm{H}_{2}$ at $873 \mathrm{~K}$ for $1 \mathrm{~h}$. In a typical oxidation test, $0.5 \mathrm{mmol}$ styrene, $1.5 \mathrm{mmol}$ TBHP, and $5 \mathrm{mg}$ catalyst were added to a $25 \mathrm{~mL}$ flask, acetonitrile used as solvents, and the temperature maintained at $355 \mathrm{~K}$. The mixture was kept vigorous stirring for another 6 hours and thereafter was 
centrifuged in order to remove the catalyst. The main products were styrene epoxide and phenylaldehyde, as verified by GC using bromobenzene as internal standard.

\section{Results and Discussion}

3.1. Physical Properties of Catalysts. Table 1 lists the BET surface area, pore volume and average pore size of the catalysts with different $\mathrm{Ag} / \mathrm{Cu}$ molar ratios. All samples display typical Langmuir type-IV isotherm with a clear adsorptiondesorption hysteresis loop (Figure 1). The pore sizes are between 16 and $21 \mathrm{~nm}$; The BET surface areas and the pore volume of the catalysts are in the range of $250 \sim 330 \mathrm{~cm}^{2} / \mathrm{g}$ and $1.05 \sim 1.67 \mathrm{~cm}^{3} / \mathrm{g}$, respectively. Compared with the results reported by Tian [20], the surface areas and the pore volume are higher than pure reticulate-like $\gamma-\mathrm{Al}_{2} \mathrm{O}_{3}$ with the values of $209 \mathrm{~m}^{2} / \mathrm{g}$ and $0.58 \mathrm{~cm}^{3} / \mathrm{g}$, which understandably provides plenty of opportunities for molecular collisions when the bimetallic samples used as a catalyst.

In addition, the EDS results show that the measured molar ratios are slightly larger than the nominal ratios, while the results confirmed by ICP are slightly lower than the nominal ratios. The difference may result from that $\mathrm{Cu}$ is more highly dispersed in alumina than $\mathrm{Ag}$ [15], which may be observed more directly compare $\mathrm{Ag} / \mathrm{Cu}$ molar ratio of $1 / 0$ to $0 / 1$ from ICP results so that the area with large black particles contains larger amounts of Ag relative to $\mathrm{Cu}$.

3.2. Morphology and Distribution. We used the microemulsion method to prepare the $\gamma$-alumina predecessor, then two metal salts microemulsion were added and chemically reduced using the $\mathrm{N}_{2} \mathrm{H}_{4} \cdot \mathrm{H}_{2} \mathrm{O}$ microemulsion as reductant. When the $\mathrm{N}_{2} \mathrm{H}_{4} \cdot \mathrm{H}_{2} \mathrm{O}$ microemulsion was slowly added to reduce the two metal ions, the colorless solution slowly turned yellow or golden brown during the reduction process, which indicated the formation of metal colloidal nanoclusters. $\gamma$-alumina with different morphologies, such as nanofibers, anomalistic spherical particles, and reticulatelike nanostructure [20] used as supports, have been investigated. Overall, it is noticed that reticulate-like nanostructure $\gamma$-Alumina has a better distribution for silver and copper because of an ordered pore structure. Figure 2(a) shows the TEM images of $\mathrm{Ag} / \mathrm{Cu}$ bimetallic particles in reticulate-like $\gamma$-Alumina. Because of the formation of silver oxide and copper oxide, the size of bimetallic particles without being reduced by $\mathrm{H}_{2}$ is between 20 to $60 \mathrm{~nm}$. After being reduced, the metallic oxides turn into metallic state, so the diameter of Ag-Cu is reduced, as shown in Figure 2(b). Unfortunately, because the $\mathrm{Ag}-\mathrm{Cu}$ nanoparticles are highly dispersed in alumina supports, it is impossible to distinguish the supports and the bimetallic particles from the TEM micrograph.

SEM micrographs (Figures 2(c) and 2(d)) show that the reticulate-like nanostructure is composed of much smaller materials in the presence of bimetallic particles. As catalyst carriers, the reticulate-like nanostructure makes the reactant molecules diffuse easily into the channels and contact conveniently with the internal active components.

In general, it is well known that the smaller particles are normally responsible for high catalytic activities.

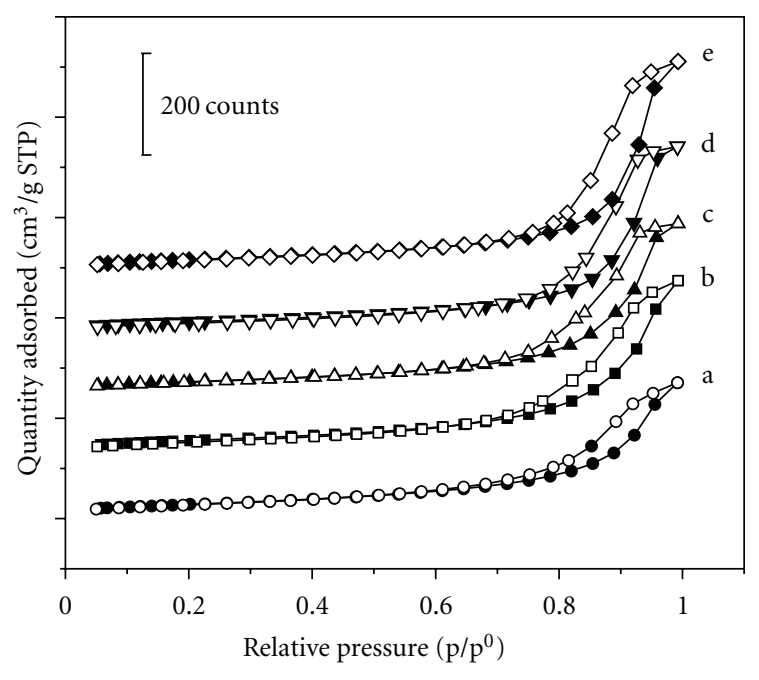

Figure 1: $\mathrm{N}_{2}$ adsorption-desorption isotherms with different $\mathrm{Ag} /$ Cu molar ratios. (a) $1 / 0$, (b) $3 / 1$, (c) $1 / 1$, (d) $1 / 3$, (e) $0 / 1$.

3.3. XPS Spectra. We conduct an X-ray photoelectron spectroscopy (XPS) characterization of the catalysts with various $\mathrm{Ag} / \mathrm{Cu}$ ratios after reduction with $\mathrm{H}_{2}$, and the results are given in Figure 3 and Table 2. The most intense peak of $\mathrm{Ag}$ $3 \mathrm{~d}$ occurs at about $368.1 \mathrm{eV}$ for the pure $\mathrm{Ag} / \gamma-\mathrm{Al}_{2} \mathrm{O}_{3}$ catalyst, and the maximum binding energy of $\mathrm{Cu} 2 \mathrm{p}$ in the pure $\mathrm{Cu} / \gamma$ $\mathrm{Al}_{2} \mathrm{O}_{3}$ is $932.4 \mathrm{eV}$. Considering the sufficient pretreatment by $\mathrm{H}_{2}$, we propose that both silver and copper are in their respective metallic state, which are confirmed by the results of IR measurement. With the increase of copper component, for the bimetallic catalyst samples, the positive peak shift (e.g., $932.4 \mathrm{eV} \rightarrow 933.7 \mathrm{eV}$ ) compared with pure $\mathrm{Cu} / \gamma-\mathrm{Al}_{2} \mathrm{O}_{3}$ suggests that there is an intimate contact between silver and copper, and the interaction from each other seems to give $\mathrm{Cu}$ a slightly greater tendency to lose electrons. Similarly, the binding energy of $\mathrm{Ag}_{3 \mathrm{~d} 5 / 2}$ for the bimetallic catalyst samples also has the same positive peak shift (e.g., $368.1 \mathrm{eV} \rightarrow$ $368.8 \mathrm{eV}$ ) compared with pure $\mathrm{Ag} / \gamma-\mathrm{Al}_{2} \mathrm{O}_{3}$, which means the interaction of two metals also enables $\mathrm{Ag}$ to exhibit a greater tendency to lose electrons [23]. At an $\mathrm{Ag} / \mathrm{Cu}$ molar ratio of $1 / 1$, the interaction between silver and copper comes to the maximum value. In summary, that the binding energy changes with the $\mathrm{Ag} / \mathrm{Cu}$ molar ratios in bimetallic catalyst samples suggests that the interaction between silver and copper leads to greater tendency to lose electrons for both metals.

3.4. Microstructural Characterization. Figure 4 shows the XRD patterns of the calcined and reduced samples with various $\mathrm{Ag} / \mathrm{Cu}$ ratios. All the samples contained four peaks positioned at $2 \theta=37.4^{\circ}, 45.9^{\circ}, 60.7^{\circ}$, and $67.4^{\circ}$, consistent with the report by $\mathrm{He}$ et al. [24], and correspond to (311), (400), (333), and (440) lattice planes of $\gamma-\mathrm{Al}_{2} \mathrm{O}_{3}$, respectively. Three peaks corresponding to the (110), (111), and (311) reflections of $\mathrm{Ag}$ are only visible in $\mathrm{b}$ and $\mathrm{c}$. In addition, the peaks corresponding to $\mathrm{Ag}$ decrease rapidly until disappear completely with the increase of the copper content. The peaks attributable to $\mathrm{Cu}$ or other copper compounds do not appear at all on the copper-containing samples, which is also 
TABLE 1: Chemical composition and textural properties of catalysts.

\begin{tabular}{|c|c|c|c|c|c|c|c|}
\hline \multicolumn{2}{|c|}{$\mathrm{Ag} / \mathrm{Cu}$ (molar ratio) } & \multicolumn{3}{|c|}{ ICP analysis } & \multirow{2}{*}{ Pore size (nm) } & \multirow{2}{*}{ Pore volume $\left(\mathrm{cm}^{3} / \mathrm{g}\right)^{\mathrm{b}}$} & \multirow{2}{*}{ BET surface area $\left(\mathrm{m}^{2} / \mathrm{g}\right)$} \\
\hline Nominal & EDS analysis $^{\mathrm{a}}$ & Ag wt $\%$ & $\mathrm{Cu} w \mathrm{t} \%$ & $\mathrm{Ag} / \mathrm{Cu}$ molar ratio & & & \\
\hline $1 / 0$ & $1 / 0$ & 1.52 & - & $1 / 0$ & 16.08 & 1.05 & 261 \\
\hline $3 / 1$ & 3.17 & 1.34 & 0.31 & 2.55 & 17.17 & 1.37 & 319 \\
\hline $1 / 1$ & 1.58 & 1.13 & 0.76 & 0.88 & 18.39 & 1.35 & 293 \\
\hline $1 / 3$ & 0.42 & 0.65 & 1.22 & 0.31 & 20.51 & 1.48 & 288 \\
\hline $0 / 1$ & $0 / 1$ & - & 1.89 & $0 / 1$ & 20.68 & 1.67 & 323 \\
\hline
\end{tabular}

${ }^{a}$ Determined before reduction by $\mathrm{H}_{2}$.

${ }^{\mathrm{b}}$ Total pore volume obtained from $\mathrm{p} / \mathrm{p}^{\circ}=0.99$.

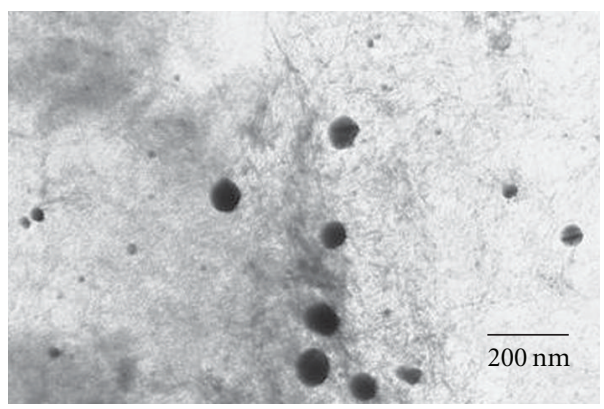

(a)

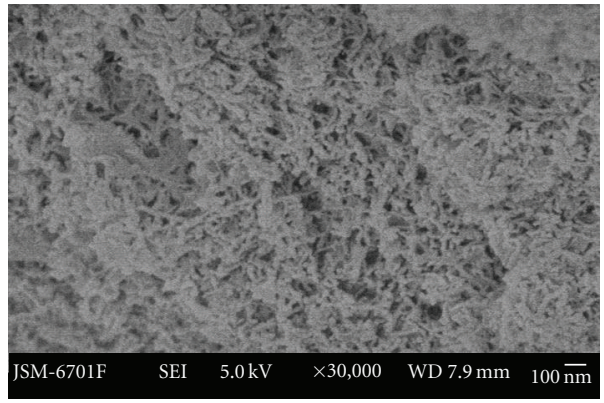

(c)

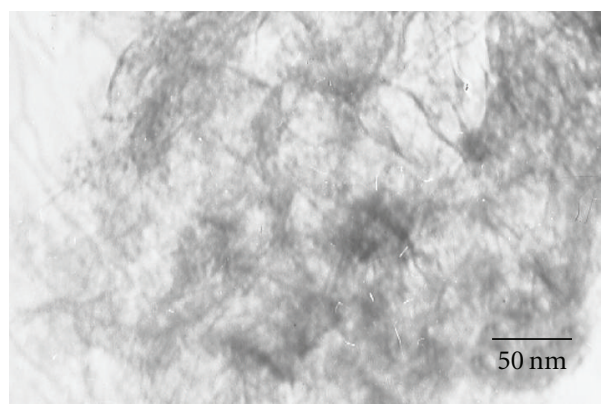

(b)

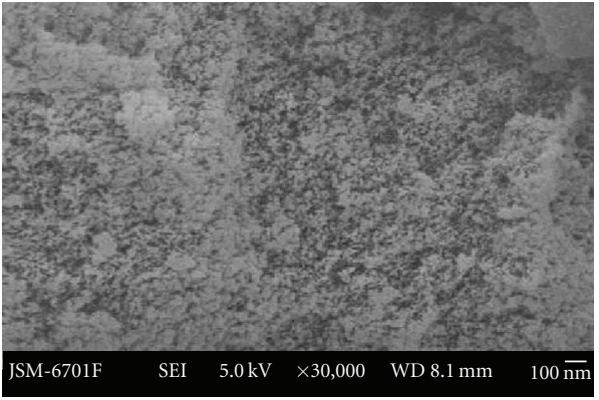

(d)

FIgURE 2: (a) TEM image of the catalysts without reducing by $\mathrm{H}_{2}, \omega=100$ calcined at $893 \mathrm{~K}$. (b) TEM image of the catalysts reduced by $\mathrm{H}_{2}$ at $873 \mathrm{~K}, \mathrm{Ag} / \mathrm{Cu}=1 / 1, \omega=100$. (c) SEM image of the reticulate-like $\gamma$-Alumina, $\omega=100$, calcined at $893 \mathrm{~K}$. (d) SEM image of the Ag-Cu/ $\gamma$-Alumina, $\omega=100, \mathrm{Ag} / \mathrm{Cu}=1 / 1$, reduction by $\mathrm{H}_{2}$ at $873 \mathrm{~K}$.

TABLE 2: Binding energies of catalysts determined by XPS.

\begin{tabular}{lcccc}
\hline Molar ratio & $\mathrm{Ag}_{3 \mathrm{~d} 5 / 2}(\mathrm{eV})$ & $\mathrm{Ag}_{3 \mathrm{~d} 3 / 2}(\mathrm{eV})$ & $\mathrm{Cu}_{2 \mathrm{p} 3 / 2}(\mathrm{eV})$ & $\mathrm{Cu}_{2 \mathrm{p} 1 / 2}(\mathrm{eV})$ \\
\hline $\mathrm{Ag} / \mathrm{Cu}=1 / 0$ & 368.1 & 374.1 & - & - \\
$\mathrm{Ag} / \mathrm{Cu}=3 / 1$ & 368.6 & 374.2 & 932.5 & 955.7 \\
$\mathrm{Ag} / \mathrm{Cu}=1 / 1$ & 368.8 & 374.4 & 933.7 & 957.1 \\
$\mathrm{Ag} / \mathrm{Cu}=1 / 3$ & 368.2 & 374.2 & 933.0 & 953.8 \\
$\mathrm{Ag} / \mathrm{Cu}=0 / 1$ & - & - & 932.4 & 953.2 \\
\hline
\end{tabular}

noticed by another group [15]. We hypothesize that a wider diffraction peaks of $\mathrm{Cu}$ leads to overlapping of the diffraction peaks of alumina.

The average crystalline size of $\gamma-\mathrm{Al}_{2} \mathrm{O}_{3}$ and $\mathrm{Ag}$ - $\mathrm{Cu}$ mixed colloids calculated by Scherrer equation [25] is to be all less than $5 \mathrm{~nm}$ (Table 3 ). The change of $\mathrm{Ag} / \mathrm{Cu}$ molar ratios has little effect on both of the crystalline size and the crystalline phase. It is clear that the average crystalline size of the $\mathrm{Ag}-\mathrm{Cu}$ mixed colloids is much smaller than the pore size of $\gamma-\mathrm{Al}_{2} \mathrm{O}_{3}$, which implies that the crystalline size is determined by the thermodynamics associated with the special nanostructure of the particles, rather than by the pore size of the support [26].

3.5. FT-IR Spectroscopy. Figure 5 shows FT-IR spectra of alumina and different molar ratio of $\mathrm{Ag} / \mathrm{Cu}$ supported on alumina. The IR absorption peaks at $3471 \mathrm{~cm}^{-1}$ and $1635 \sim$ $1350 \mathrm{~cm}^{-1}$ for all samples are due to $\mathrm{H}-\mathrm{OH}$ vibrations of $\mathrm{H}_{2} \mathrm{O}$, whilst the bands at $584 \mathrm{~cm}^{-1}$ and $778 \mathrm{~cm}^{-1}$ are attributed to Al-O vibration of $\gamma-\mathrm{Al}_{2} \mathrm{O}_{3}$ [27], consistent with the result of XRD. No peaks of other compounds appear in all samples, which are generally regarded as the proof of totally reduction of $\mathrm{Ag} / \mathrm{Cu}$ by $\mathrm{H}_{2}$.

3.6. Oxidation of Styrene. Styrene epoxidation catalyzed by $\mathrm{Ag}-\mathrm{Cu} / \gamma-\mathrm{Al}_{2} \mathrm{O}_{3}$ complex at various molar ratios has been 


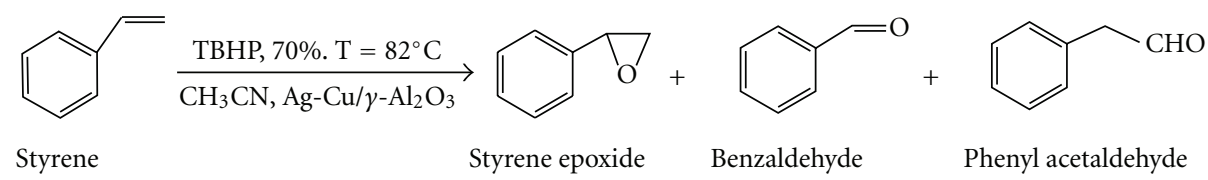

SCHEMe 1: Reaction of styrene oxidation by $\mathrm{Ag}-\mathrm{Cu} / \gamma-\mathrm{Al}_{2} \mathrm{O}_{3}$ catalysts.

TABLe 3: The crystalline size of $\mathrm{Ag}$ and $\mathrm{Al}_{2} \mathrm{O}_{3}$. Angle $2 \theta$, corrected half width $(\beta)$, corresponding to (111) peak of Ag and (440) peak of $\gamma-\mathrm{Al}_{2} \mathrm{O}_{3}$ and particles diameter "d" after Scherrer equation for $\mathrm{Ag}$-Cu colloids supported on $\gamma-\mathrm{Al}_{2} \mathrm{O}_{3}$.

\begin{tabular}{|c|c|c|c|c|c|c|}
\hline \multirow{2}{*}{$\mathrm{Ag} / \mathrm{Cu}$} & \multicolumn{3}{|c|}{ For Ag colloids } & \multicolumn{3}{|c|}{ For $\mathrm{Al}_{2} \mathrm{O}_{3}$ colloids } \\
\hline & $2 \theta\left(^{\circ}\right)$ & $\beta\left(^{\circ}\right)$ & “d” (nm) & $2 \theta\left(^{\circ}\right)$ & $\beta\left(^{\circ}\right)$ & “d” (nm) \\
\hline $\mathrm{Al}_{2} \mathrm{O}_{3}$ & n.c. & n.c. & n.c. & 66.005 & 0.056 & 2.92 \\
\hline $1 / 0$ & 37.690 & 0.029 & 4.98 & 65.846 & 0.059 & 2.77 \\
\hline $3 / 1$ & 37.382 & 0.029 & 4.99 & 67.846 & 0.042 & 3.93 \\
\hline $1 / 1$ & 37.382 & 0.029 & 4.99 & 67.846 & 0.063 & 2.62 \\
\hline $1 / 3$ & n.c. & n.c. & n.c. & 65.905 & 0.063 & 2.59 \\
\hline $0 / 1$ & n.c. & n.c. & n.c. & 66.136 & 0.046 & 3.56 \\
\hline
\end{tabular}

TABLE 4: Styrene epoxidation at different ratio of $\mathrm{Ag} / \mathrm{Cu}$ supported on $\gamma-\mathrm{Al}_{2} \mathrm{O}_{3}^{\mathrm{a}}$.

\begin{tabular}{|c|c|c|c|c|c|}
\hline \multirow{2}{*}{ Entry } & \multirow{2}{*}{$\mathrm{Ag} / \mathrm{Cu}$ molar ratio } & \multirow{2}{*}{ Conversion $(\%)^{\mathrm{b}}$} & \multicolumn{3}{|c|}{ Selectivity $(\%)^{\mathrm{b}}$} \\
\hline & & & Epoxide & Benzaldehyde & Phenyl acetaldehyde \\
\hline $\bar{I}$ & No catalyst & 37.4 & None & $>99.9$ & c \\
\hline II & $\gamma-\mathrm{Al}_{2} \mathrm{O}_{3}$ & 42.1 & 49.6 & 46.6 & 3.8 \\
\hline 1 & $\mathrm{Ag}: \mathrm{Cu}=1: 0 / \gamma-\mathrm{Al}_{2} \mathrm{O}_{3}$ & 89.7 & 65.6 & 34.4 & c \\
\hline 2 & $\mathrm{Ag}: \mathrm{Cu}=3: 1 / \gamma-\mathrm{Al}_{2} \mathrm{O}_{3}$ & 93.5 & 76.6 & 23.4 & c \\
\hline 3 & $\mathrm{Ag}: \mathrm{Cu}=1: 1 / \gamma-\mathrm{Al}_{2} \mathrm{O}_{3}$ & 94.6 & 66.9 & 33.1 & c \\
\hline 4 & $\mathrm{Ag}: \mathrm{Cu}=1: 3 / \gamma-\mathrm{Al}_{2} \mathrm{O}_{3}$ & 87.5 & 62.0 & 38.0 & c \\
\hline 5 & $\mathrm{Ag}: \mathrm{Cu}=0: 1 / \gamma-\mathrm{Al}_{2} \mathrm{O}_{3}$ & 83.7 & 20.4 & 79.6 & c \\
\hline
\end{tabular}

${ }^{a}$ Reaction conditions: $\mathrm{Ag}-\mathrm{Cu} / \gamma-\mathrm{Al}_{2} \mathrm{O}_{3}$ catalyst $5 \mathrm{mg}, \mathrm{CH}_{3} \mathrm{CN} 2 \mathrm{~mL}$, styrene $0.5 \mathrm{mmol}$, TBHP $1.5 \mathrm{mmol}, 82^{\circ} \mathrm{C}, 6 \mathrm{~h}$.

${ }^{b}$ Determined by GC; use bromobenzene as internal standard, the correction factor is 1.27.

'Product not detected.

studied using tert-butyl hydroperoxide (TBHP) as oxidant (based on reaction Scheme 1). The mixed organic phase after reaction is sampled for off-line GC analysis, and it is confirmed that benzaldehyde and styrene oxide are the main products in this catalytic system. Using bromobenzene as internal standard, the correction factor is 1.27 , and the results of the styrene oxidation are summarized in Table 4. As can be seen from the results, the conversion of styrene has been improved with addition of either Ag or Cu. In contrast, in the simultaneous presence of copper and silver, that is, Ag$\mathrm{Cu}$ bimetallic catalysts, much higher catalytic activity was shown than that of the corresponding monometallic silver or copper supported on $\gamma-\mathrm{Al}_{2} \mathrm{O}_{3}$ catalysts. It is proposed that the addition of copper can help to improve the conversion of styrene, whereas the role of silver is to adjust the selectivity of styrene epoxide. Therefore, the selectivity of styrene epoxide can be controlled by adjusting the $\mathrm{Ag} / \mathrm{Cu}$ molar ratio. The maximum selectivity of styrene epoxide (up to $76.6 \%$ ) appears at $\mathrm{Ag} / \mathrm{Cu}$ molar ratio of 3/1, as the conversion of styrene is up to $93.5 \%$. Additionally, owing to the maximum value of the interaction between silver and copper at $\mathrm{Ag} / \mathrm{Cu}$ molar ratio of $1 / 1$, the maximum conversion $(94.6 \%)$ appears. A possible mechanism may be that peroxidic oxygen adsorbs on Ag, while styrene molecules are adsorbed on the crystal surface of $\mathrm{Cu}$; initial complex formation between bimetallic catalyst and tert-butyl hydroperoxide renders the peroxidic oxygen more electrophilic and hence more labile to attack by an olefinic double bond [6]; meanwhile, XPS results demonstrate that the silver and copper components are in intimate contact with each other so that the $\mathrm{O}_{2}{ }^{-}$adsorbed on the silver surface can migrate to the copper surface and react with the adsorbed styrene easily. However, on the basis of the ratio of $1 / 1$, further larger copper content causes lower conversion, styrene oxide selectivity for $\mathrm{Cu}$ is more metallic activity than $\mathrm{Ag}$, and a number of copper oxides might be formed during the reaction process for the excess oxidant. Then, the presence of copper oxides perhaps prevent the further reaction [28], and wherefore $\mathrm{Cu}$ shows the lowest conversion, and the conversion of $1 / 3(\mathrm{Ag} / \mathrm{Cu})$ catalyst is lower than that of $\mathrm{Ag} / \mathrm{Cu}$ at the ratio of $1 / 0$. In addition, the styrene oxide selectivity decreases with addition of copper component from $\mathrm{Ag} / \mathrm{Cu}$ molar ratio of $3 / 1$ to $1 / 3$, which may be attributed to the unstable styrene oxide product in the presence of massive copper. In such conditions, the oxidation of metallic $\mathrm{Cu}$ by styrene oxide perhaps becomes a favored reaction. 


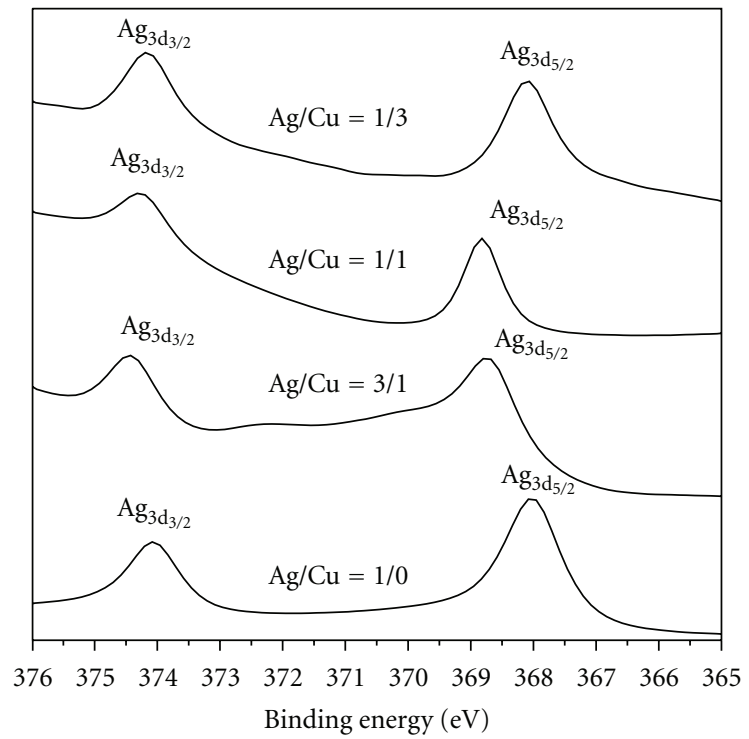

(a)

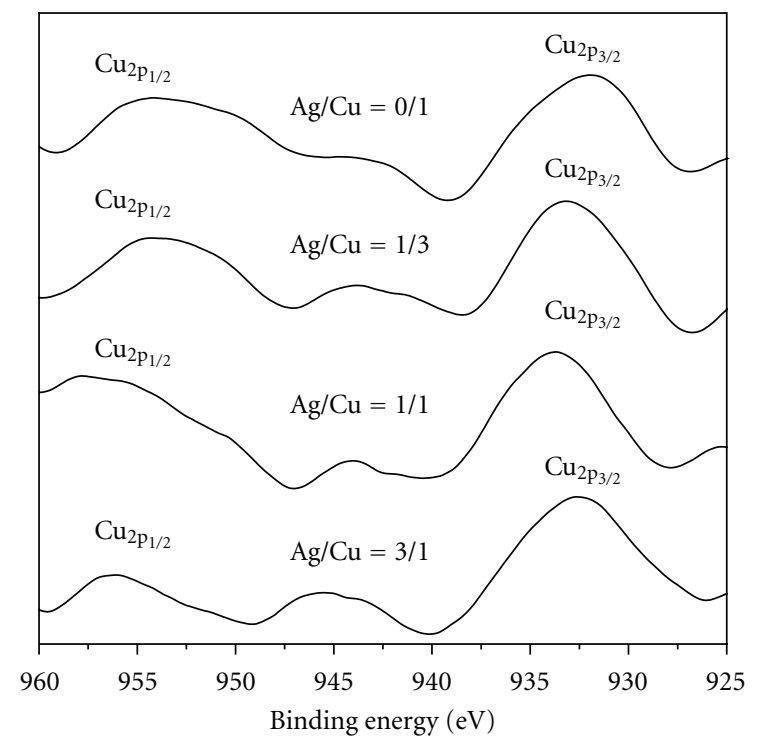

(b)

FIgURE 3: XPS spectra of Ag-Cu/ $\gamma$-alumina with different $\mathrm{Ag} / \mathrm{Cu}$ molar ratios.

\section{Conclusions}

In summary, we have developed a microemulsion method for loading Ag-Cu bimetallic nanoparticles confined in $\gamma$ alumina at room temperature, and the physicochemical properties have been investigated. Detailed studies by XRD, TEM, and SEM methodology reveal that the new Ag-Cu bimetallic nanoparticles supported on the reticulate-like $\gamma$ alumina distribute evenly and have smaller size. It is interinterestingesting to note that there is an interaction between silver and copper that makes both metals have a greater tendency to lose electrons. Furthermore, high activity in the oxidation of styrene is observed using the synthesized materials as catalysts, which may be due to the

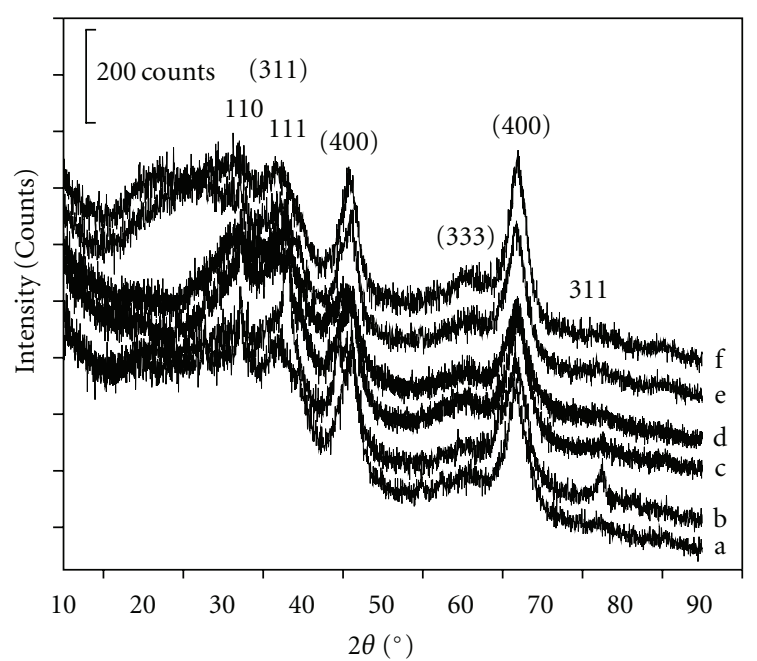
(a) $\mathrm{Al}_{2} \mathrm{O}_{3}$
(d) $\mathrm{Ag} / \mathrm{Cu}=1 / 1$
(b) $\mathrm{Ag} / \mathrm{Cu}=1 / 0$
(e) $\mathrm{Ag} / \mathrm{Cu}=1 / 3$
(c) $\mathrm{Ag} / \mathrm{Cu}=3 / 1$
(f) $\mathrm{Ag} / \mathrm{Cu}=0 / 1$

Figure 4: Wide-angle XRD patterns of $\gamma-\mathrm{Al}_{2} \mathrm{O}_{3}$ and $\mathrm{Ag}-\mathrm{Cu}$ bimetallic nanoparticles supported on $\gamma-\mathrm{Al}_{2} \mathrm{O}_{3}$ at various molar ratios. [Metal salts] $/\left[\mathrm{N}_{2} \mathrm{H}_{5} \mathrm{OH}\right]=1 / 10 ; \omega=100$; reaction time = $2.5 \mathrm{~h}$; All samples were reduced by $\mathrm{H}_{2}$ at $873 \mathrm{~K}$ and $\gamma-\mathrm{Al}_{2} \mathrm{O}_{3}$ was calcined at $893 \mathrm{~K}$.

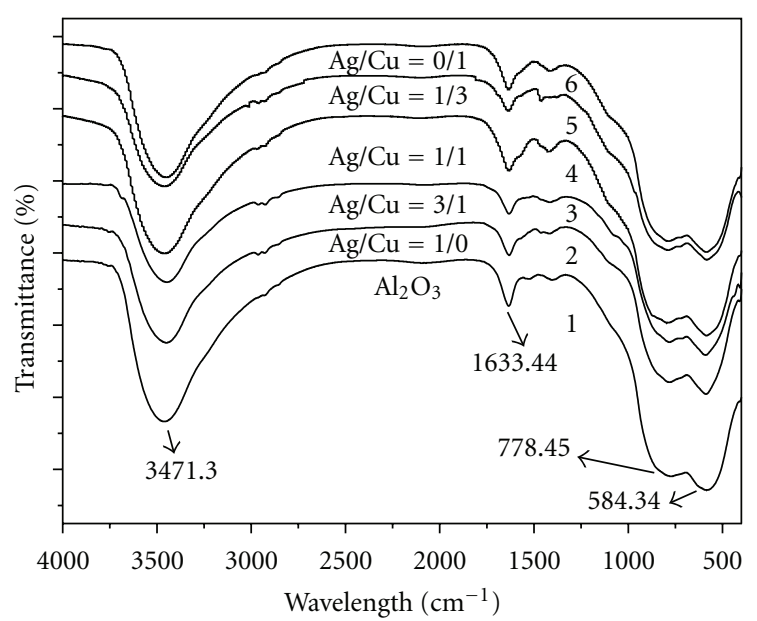
(1) $\mathrm{Al}_{2} \mathrm{O}_{3}$
(4) $1 / 1$
(2) $1 / 0$
(5) $1 / 3$
(3) $3 / 1$
(6) $0 / 1$

FIGURE 5: FTIR spectra of alumina and different molar ratio of $\mathrm{Ag} / \mathrm{Cu}$ supported on alumina.

interaction between silver and copper: Ag plays a key role in adsorption of $\mathrm{O}_{2}{ }^{-}$and mainly catalyzes styrene epoxidation to styrene epoxide. Instead, $\mathrm{Cu}$ provides more active sites for adsorbing styrene, whilst $\mathrm{O}_{2}{ }^{-}$adsorbed on the silver surface can migrate to the copper surface and react with the adsorbed styrene easily. So, the selectivity of styrene oxide has a close relationship with the amount of $\mathrm{Ag}$ and can be controlled by adjusting molar ratio of $\mathrm{Ag} / \mathrm{Cu}$. In addition, the minimum consumption of noble metals makes the catalysts 
cost effective. Bimetallic catalysts prepared herein may also be promising candidates for applications in many other reactions such as in $\mathrm{CO}$ oxidation.

\section{Acknowledgments}

The authors kindly thank Jianxi Liu, State Key Laboratory of Solid Lubrication, Lanzhou Institute of Chemical Physics, Chinese Academy of Sciences, for assistance with the XPS measurements. Financial support was provided by the National Natural Science Foundation of China (Projects nos. 20603014, 20673059, and 20973061), the Chinese Ministry of Education (Key project 105074), the Committee of Science and Technology of Shanghai (Projects nos. 0652nm010 and 08JC1408100), and the Fundamental Research Funds for the Central Universities (Project lzujbky-2011-116).

\section{References}

[1] C.-W. Yen, M.-L. Lin, S.-A. Wang, S.-A. Chen, J.-M. Chen, and C.-Y. Mou, "CO oxidation catalyzed by Au-Ag bimetallic nanoparticles supported in mesoporous silica," Journal of Physical Chemistry C, vol. 113, no. 41, pp. 17831-17839, 2009.

[2] M. Enever, S. Linic, K. Uffalussy, J. M. Vobs, and M. A. Barteau, "Synthesis, structure, and reactions of stable oxametallacycles from styrene oxide on $\operatorname{Ag}(111)$," Journal of Physical Chemistry B, vol. 109, no. 6, pp. 2227-2233, 2005.

[3] J.-H. Liu, A.-Q. Wang, Y.-S. Chi, H.-P. Lin, and C.-Y. Mou, "Enhancing stability and oxidation activity of cytochrome $\mathrm{c}$ by immobilization in the nanochannels of mesoporous aluminosilicates," Journal of Physical Chemistry B, vol. 109, no. 25, pp. 40-43, 2005.

[4] K. Arve, K. Svennerberg, F. Klingstedt et al., "Structureactivity relationship in HC-SCR of $\mathrm{NO}_{x}$ by TEM, $\mathrm{O}_{2}$-chemisorption, and EDXS study of $\mathrm{Ag} / \mathrm{Al}_{2} \mathrm{O}_{3}$," Journal of Physical Chemistry B, vol. 110, no. 1, pp. 420-427, 2006.

[5] Z.-M. Wang, M. Yamaguchi, I. Goto, and M. Kumagai, "Characterization of $\mathrm{Al}_{2} \mathrm{O}_{3}$ de- $\mathrm{NO}(\mathrm{x})$ catalysts by probing surface acidity and basicity of the supporting substrate," Physical Chemistry Chemical Physics, vol. 2, no. 13, pp. 3007-3015, 2000.

[6] E. Zhan, Y. Li, J. Liu, X. Huang, and W. Shen, "Corrigendum to " $\mathrm{A} \mathrm{VO}_{x} /$ meso- $\mathrm{TiO}_{2}$ catalyst for methanol oxidation to dimethoxymethane" [Catal. Commun. 10 (2009) 20512055]," Catalysis Communications, vol. 11, no. 3, p. 225, 2009.

[7] J. T. Roberts and R. J. Madix, "Epoxidation of olefins on silver: conversion of norbornene to norbornene oxide by atomic oxygen on $\operatorname{Ag}(110)$," Journal of the American Chemical Society, vol. 110 , no. 25 , pp. 8540-8541, 1988.

[8] J. J. Cowell, A. K. Santra, and R. M. Lambert, "Ultraselective epoxidation of butadiene on Cu111 and the effects of Cs promotion," Journal of the American Chemical Society, vol. 122, no. 10, pp. 2381-2382, 2000.

[9] J. J. Cowell, A. K. Santra, R. Lindsay, R. M. Lambert, A. Baraldi, and A. Goldoni, "Bonding and reactivity of styrene on $\mathrm{Cu}(110)$ : heterogeneous alkene epoxidation without the use of silver," Surface Science, vol. 437, no. 1, pp. 1-8, 1999.

[10] J. H. Sinfelt, “Supported “bimetallic cluster” catalysts," Journal of Catalysis, vol. 29, no. 2, pp. 308-315, 1973.

[11] N. Toshima, M. Harada, T. Yonezawa, K. Kushihashi, and K. Asakura, "Structural analysis of polymer-protected $\mathrm{Pd} / \mathrm{Pt}$ bimetallic clusters as dispersed catalysts by using extended Xray absorption fine structure spectroscopy," Journal of Physical Chemistry, vol. 95, no. 19, pp. 7448-7453, 1991.

[12] X. Wang, N. Li, L. D. Pfefferle, and G. L. Haller, "PtCo bimetallic catalyst supported on single-walled carbon nanotubes: effect of alloy formation and oxygen containing groups," Journal of Physical Chemistry C, vol. 114, no. 40, pp. 16996-17002, 2010.

[13] L. Zhao, K. Fang, D. Jiang, D. Li, and Y. Sun, "Sol-gel derived Ni-Mo bimetallic carbide catalysts and their performance for CO hydrogenation," Catalysis Today, vol. 158, no. 3-4, pp. 490495, 2010.

[14] V. V. Agrawal, P. Mahalakshmi, G. U. Kulkarni, and C. N. R. Rao, "Nanocrystalline films of Au-Ag, $\mathrm{Au}-\mathrm{Cu}$, and Au-Ag$\mathrm{Cu}$ alloys formed at the organic-aqueous interface," Langmuir, vol. 22, no. 4, pp. 1846-1851, 2006.

[15] L. Gang, B. G. Anderson, J. Van Grondelle et al., "Aluminasupported $\mathrm{Cu}$-Ag catalysts for ammonia oxidation to nitrogen at low temperature," Journal of Catalysis, vol. 206, no. 1, pp. 60-70, 2002.

[16] X. Yang, S. Gao, and Z. Xi, "Reaction-controlled phase transfer catalysis for styrene epoxidation to styrene oxide with aqueous hydrogen peroxide," Organic Process Research \& Development, vol. 9, no. 3, pp. 294-296, 2005.

[17] D.-H. Chen and C.-J. Chen, "Formation and characterization of Au-Ag bimetallic nanoparticles in water-in-oil microemulsions," Journal of Materials Chemistry, vol. 12, pp. 1557-1562, 2002.

[18] L. Qi, J. Ma, and J. Shen, "Synthesis of copper nanoparticles in nonionic water-in-oil microemulsions," Journal of Colloid and Interface Science, vol. 186, no. 2, pp. 498-500, 1997.

[19] H. Liu, X. Du, P. Gao, J. Zhao, J. Fang, and W. Shen, “Distinct magnetic properties of one novel type of nanoscale cobaltiron Prussian blue analogues synthesized in microemulsion," Journal of Magnetism and Magnetic Materials, vol. 322, no. 5, pp. 572-577, 2010.

[20] L. Tian, Study on the preparation of $\gamma$-alumina nanomaterials by microemulsion and microemulsion hydrothermal synthesis, M.S. thesis, Lanzhou University, Lanzhou, China, 2008.

[21] H. H. Ingelsten, J.-C. Béziat, K. Bergkvist et al., "Deposition of platinum nanoparticles, synthesized in water-in-oil microemulsions, on alumina supports," Langmuir, vol. 18, no. 5, pp. 1811-1818, 2002.

[22] J. Zhao, L. Tian, J. Fang, and W. Shen, "China patent 200810093754.0," 2008.

[23] A.-Q. Wang, J.-H. Liu, S.D. Lin, T.-S. Lin, and C.-Y. Mou, "A novel efficient Au-Ag alloy catalyst system: preparation, activity, and characterization," Journal of Catalysis, vol. 233, no. 1, pp. 186-197, 2005.

[24] Z. He, A. Zhang, S. Song et al., " $y-\mathrm{Al}_{2} \mathrm{O}_{3}$ modified with praseodymium: an application in the heterogeneous catalytic ozonation of succinic acid in aqueous solution," Industrial and Engineering Chemistry Research, vol. 49, no. 24, pp. 1234512351, 2010.

[25] B. E. Warren, X-Ray Diffraction, Addison-Wesley, Reading, Mass, USA, 1969.

[26] X. Liu, A. Wang, X. Wang, C.-Y. Mou, and T. Zhang, “ $\mathrm{Au}-\mathrm{Cu}$ Alloy nanoparticles confined in SBA-15 as a highly efficient catalyst for COoxidation," Chemical Communications, no. 17, pp. 3187-3189, 2008.

[27] S. Ramesh, E. Sominska, B. Cina, R. Chaim, and A. Gedanken, "Nanocrystalline $\gamma$-alumina synthesized by sonohydrolysis of 
alkoxide precursor in the presence of organic acids: structure and morphological properties," Journal of the American Ceramic Society, vol. 83, no. 1, pp. 89-94, 2000.

[28] J. R. Monnier and G. W. Hartley, "Phase transition in Langmuir films of octadecylmalonic acid," Journal of Catalysis, vol. 203, no. 2, pp. 529-531, 2001. 

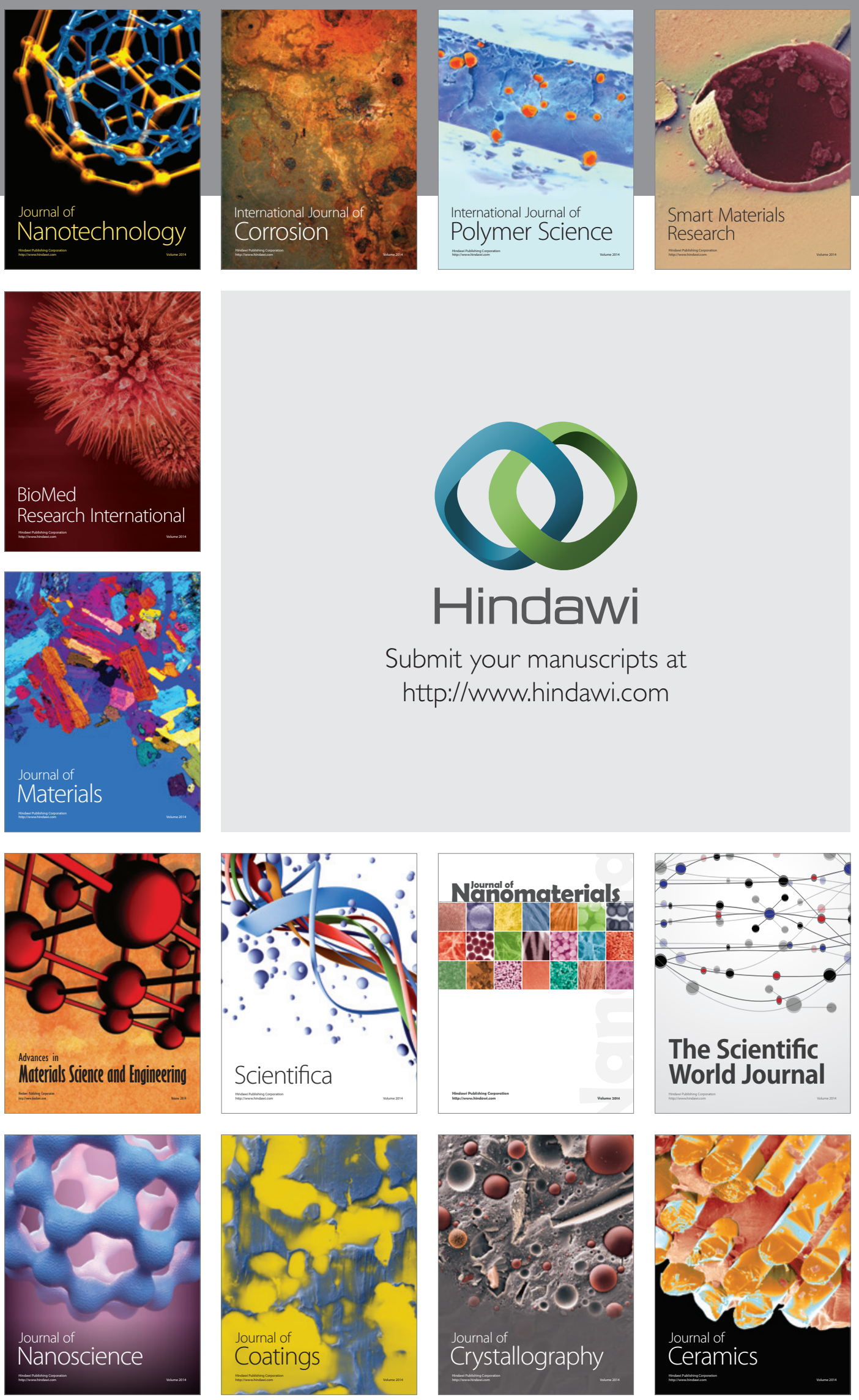

The Scientific World Journal

Submit your manuscripts at

http://www.hindawi.com

\section{World Journal}

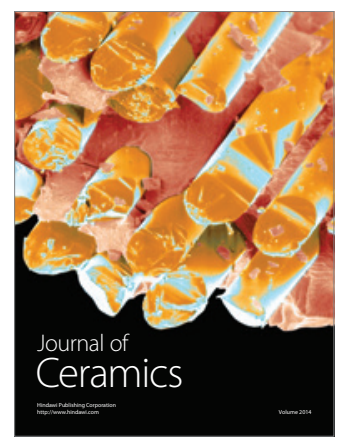

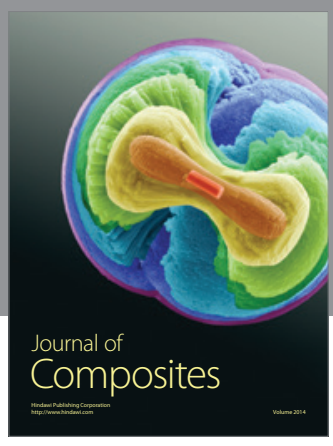
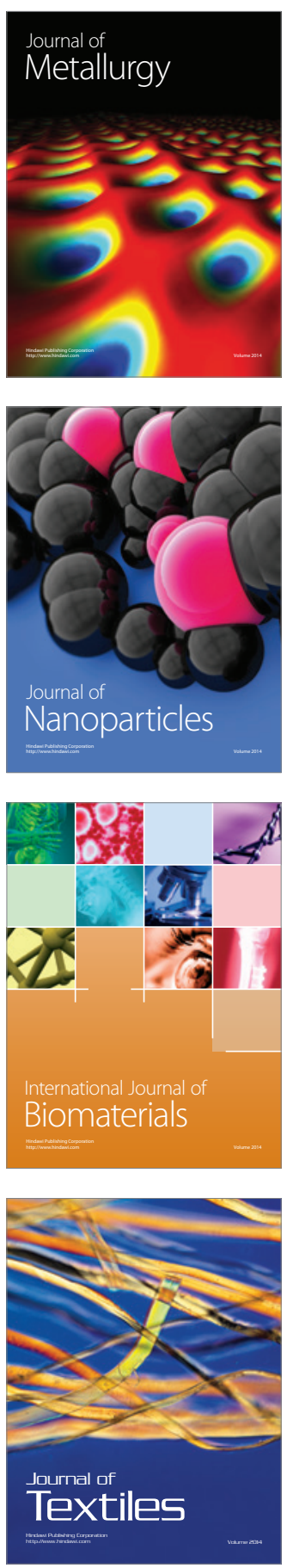